\title{
Analysis and Research on Outcomes-based Education
}

\author{
Xinfeng Yang ${ }^{a}$ and Lingxiao Zhang ${ }^{b}$ \\ School of Computer and Information Engineering, Nanyang Institute of Technology, Nanyang, \\ China \\ a1832370485@qq.com, bnitzlx@163.com
}

\begin{abstract}
Keywords: Outcomes-based education; Principle; Implementation; Step
\end{abstract}
\begin{abstract}
Results-oriented education as an advanced educational philosophy, has been the people's attention and recognition, and has become the United States, Britain, Canada and other countries the mainstream of educational reform concept. The American Engineering Education Accreditation Association (A-BET) has fully accepted the OBE concept and has been pursued throughout the engineering education certification standard. This paper analyzes and studies the OBE from the aspects of basic principles, implementation principles and key steps.
\end{abstract}

\section{Introduction}

In order to meet the challenges of higher industrial education for higher engineering education, and in order to adapt to the rise of public accountability, people pay more attention to the return of educational inputs and the real needs have real output. In this context, the Outcomes-based Education (OBE) was first proposed by Spady in 1981 to define OBE as "clearly focusing and organizing the education system to ensure that students in the future life to obtain substantial success experience." He believes that OBE to achieve the transformation of the paradigm of education. Because, in the OBE education model, students learn what and how success is far more important than how to learn and when to learn [1]. After OBE at an alarming rate to obtain a wide range of attention and application, after 10 years after the development of the formation of a relatively complete theoretical system, is still considered the pursuit of excellence in the correct direction of education. American Engineering Education Certification Association fully accepted the concept of OBE, and it runs through the engineering education certification standards. In June 2013, China was accepted as a member of the "Washington Agreement". It is of practical significance to guide the reform of engineering education with the idea of oriented education.

\section{OBE Basic Principles}

The basic principle of the OBE concept is that all learners are successful (Success for All) [2]. The logical framework of this idea is that each student is talented and that learning should be based on cooperation rather than competition, and that schools should be educational institutions that find successful ways for each student.

Spady based on the educational philosophy based on the 1994 proposed results-oriented education pyramid structure. This structure divides results into education into five areas: an implementation paradigm, two key objectives, three key premises, four executive principles, and five implementation points. "An example of implementation" means that the implementation of OBE should have a clear vision and framework at the beginning. This vision and framework should clearly clarify the competencies that students should have in their field of expertise and focus on specific competencies to design the teaching objectives, curriculum organization, and teacher teaching, and teaching evaluation. "Two key goals" refers to building blueprints and creating success scenarios and opportunities. The blueprint of the results should indicate the sufficient knowledge that the students should have the knowledge, the ability and the value to pursue at the time of graduation and the creation of the successful situation and the opportunity is the sufficient condition for the realization of the result blueprint. "Three key prerequisites" means "all students can learn and succeed", "the school's work will directly affect student learning" and "successful 
learning can promote more successful learning." In the OBE concept, "four executive principles" by the national scholars inherit and practice. The four principles are summarized as follows: First, clear focus, the focus is the important peak results; Second, down the design, from the final, the peak results down to create; Third, the high expectations, expect all students to be successful; Fourth, the expansion of opportunities to enhance the success of learning opportunities. Jobs Brandt further elaborates on the above four principles from the perspective of instructional design. He believes that the culmination of a clear focus should be on the ability of the student to demonstrate the combined application of the entire learning process, rather than the week, semester, or year of school activity itself. Down design is the peak performance for the ultimate goal, curriculum and teaching design return to students with the ability to go. The high expectation means that the teacher should regard the student's learning process as a high-level challenge of self-realization of the student, not to set the general standard for the student, but should expect the students to achieve self-realization. The opportunity for extension requires teachers to respond to the individual needs of the student in a more flexible manner and to create opportunities for students to practice what they have learned to prove the validity and usefulness of their learning. "Five implementation points" include clear learning outcomes, construction of the curriculum system, clarity of teaching strategies, and the formation of self-reference evaluation and gradually reached the peak of five levels[3].

OBE has three types of applications at the application level: traditional OBE with emphasis on professional skills and its structural performance; transitional OBE that emphasizes unstructured performance and high-level competencies; focus on life role capability and transition from complex role performance OBE. Traditional OBE learning outcomes can be divided into two levels: professional skills and structural performance. In the professional skills level, by the teacher in advance to develop professional courses content and professional scores to study the results of the evaluation. The structural performance is reflected in the students to achieve the results of professional skills and the implementation of specific projects, modules and steps. Compared with the former type, the transitional OBE emphasizes that the purpose of school existence is to cultivate students' knowledge, ability and characteristics that conform to the future citizen orientation. And based on the contemporary curriculum structure and teaching model under the school teaching concept cannot cultivate in the future complex and challenging high-tech living environment achievements of students. Therefore, the core of the concept of transition OBE is based on the future orientation of learning outcomes oriented. Transitional OBE is between the first two, emphasizing the high level of ability and non-structural performance of learning outcomes. High level competence here is not limited to specific subject knowledge, especially with the ability to use critical thinking through the synthesis of knowledge to solve practical problems. The so-called non-structural performance points to the performance in the more complex work need to integrate knowledge from different perspectives or design their own learning program and determine its scope, the implementation of standards and evaluation methods.

\section{The Implementation of OBE}

Clear focus: curriculum design and teaching to clearly focus on students in the completion of the learning process can be achieved after the final learning outcomes, and allow students to focus their learning objectives in these learning outcomes. Teachers must clearly articulate and work to help students develop knowledge, ability and realm so that they can achieve the desired results. Clearly focused on the principles of OBE implementation of the most important and most basic principles, this is because: First, can help teachers to develop a learning curve is clearly expected students learning blueprint; Second, the learning blueprint as a curriculum, teaching, evaluation The design and implementation of the starting point, and all the learning closely; Third, whether it is teaching design or teaching evaluation, are to enable students to fully demonstrate their learning outcomes as the premise; Fourth, from the first classroom teaching until Finally, teachers and students, like partners, work hard to share every moment [4].

Expand the opportunity: curriculum design and teaching to fully consider the individual differences in each student, to be in time and resources to protect each student has the opportunity 
to achieve learning outcomes. Schools and teachers should not provide the same learning opportunities to all students at the same time in the same way, but should be in a more flexible way to meet the student's individual requirements so that students have the opportunity to prove that they have learned and displayed their learning outcomes. If students get the right learning opportunities, I believe they will achieve the desired learning outcomes [5].

Improve expectations: teachers should improve the expectations of students learning, the development of challenging implementation of standards to encourage students to learn in depth, to promote more successful learning. There are three main aspects of improvement: one is to improve the implementation of standards to promote students to complete the learning process to achieve a higher level; the second is to exclude the success of the additional conditions to encourage students to achieve peak performance; third is to add high-level courses to guide students to High standard effort.

Reverse design: the final goal (the final learning results or peak results) as a starting point, reverse curriculum design, teaching activities. The curriculum and instructional design are designed from the final outcome of the study (the culmination of the outcome) to determine the appropriateness of all the teaching towards peak outcomes. The starting point of teaching is not what teachers want to teach, but what is needed to achieve peak results. Reverse design to master the two principles: First, students expect to achieve the peak results to reverse, continue to increase the difficulty of the course to guide students to achieve peak results; the second is to focus on important, basic, core and peak results, Less necessary courses or more important courses to replace, in order to effectively assist students to successfully study.

\section{Implementation Steps for OBE}

In particular, the implementation and implementation of OBE has the following four steps:

\section{Develop Professional Training Objectives and Expected Learning Outcomes}

According to the requirements of the engineering education certification system, the training goal is to describe the professional and professional achievements that can be achieved in the professional about 5 years after graduation. The graduation requirement is a detailed description of the knowledge and ability that students should master when graduation through the professional knowledge, skills and literacy.

The difference between the training goal and the learning achievement is that the training goal is more abstract than the learning achievement. The learning achievement is more specific than the training goal. The learning achievement must be determined according to the professional training goal. The achievement of the training goal must be checked by the evaluation of the learning achievement. The Professional training objectives is not only the implementation of results-oriented education starting point, but also the basic basis for testing the results of education. So, how to develop professional training objectives?

The development of professional training objectives must involve the participation of key stakeholders. Often, the main stakeholders in engineering education include engineering teachers, graduate employers, employers, graduates alumni and school students.

According to professional training objectives, develop a clear professional student learning outcomes, and asked to cover the engineering education professional certification standards in the study results.

Professional training objectives are not static, but the need for regular inspection and revision.

\section{Establish the Learning Outcomes and the Relevance of the Curriculum System}

Learning outcomes are the basis for curriculum design and design, and the course is the carrier of the learning achievement and the "runway". Only through the study of learning results through the curriculum design, learning outcomes and courses between the establishment of organic association, it is possible to ensure that the certification standards "landing."

The main task of establishing the two links is to analyze and examine the whole professional curriculum system from the learning achievement, and to establish the correspondence and the 
relationship between the learning achievement and the curriculum system comprehensively and systematically.

\section{Establish the Relationship between Learning Outcomes and Teaching Content}

In accordance with the learning-oriented curriculum design, a course decided to teach what (ie, teaching content or syllabus design), should be based on pre-developed learning outcomes. In other words, the results of the study should be implemented one by one to the curriculum of each course to go, so as to clear a specific course of teaching content to achieve the contribution of learning outcomes.

When writing a syllabus based on the results-oriented instructional design, it is necessary to first clarify which of the courses to achieve the achievement of the learning achievement, and then determine the corresponding teaching content for each of these learning outcomes and then determine the completion The number of teaching hours required for these teaching contents.

\section{Evaluate the achievement of learning Outcomes}

The assessment includes periodic and occasional assessments. The purpose of the assessment is two, one is the formation of assessment, that is, to collect students to learn the information to improve the curriculum and teaching; Second, the summary assessment, usually in order to make the results of student learning to make value judgments, may be related to students interest.

\section{Conclusion}

OBE model has many advantages, but if the operation is not appropriate, it is likely to evolve into behavioral manipulation under the rigid process, so that education loss of basic humanistic care. The implementation of high-level and high-quality OBE engineering education model, the quality of teacher education theory put forward a high demand. First, ask the teacher to establish a good learning output, and its decomposition can be manipulated to refine the target. Second, teachers are required to be good at using all kinds of educational resources, flexible choice of various educational strategies to achieve the desired educational goals. Third, teachers are required to master a variety of teaching evaluation methods, dynamic grasp of the level of development of students' knowledge, ability and attitudes. Fourth, teachers are required to teach each other, for each student to set up a personalized development program. OBE education model puts forward high demands on teachers' teaching input. If we cannot change the current situation of "re-research and light teaching" in colleges and universities, OBE cannot mobilize the enthusiasm of teachers to participate in teaching reform. OBE cannot be sustainable.

\section{Acknowledgement}

The author is grateful to the support of Nanyang Institute of Technology Education and Teaching Reform Research Project.

\section{References}

[1] P.H.Gu, W.L.Hu, P.Lin. Research in Higher Education of Engineering, (2014) No.1, p.27.

[2] W.G.Spady, K.G.Marshall. Educational Leadership, (1991) No.2, p.65.

[3] T.E.Shen, L.Steven. Journal of Higher Education Management, Vol.10 (2015) No.9, p.21.

[4] M.Y.Pan: New Higher Education (Beijing Normal University Press, China 1996), p.12.

[5] Z.Y.Li. Chinese University Teaching, (2015) No.3, p.32. 